\title{
Evangelização e revitalização urbana
}

\author{
Evangelization and urban revitalization
}

\author{
Josefa Alves dos Santos
}

\section{Resumo}

O presente artigo objetiva compreender e refletir sobre o sentido dos projetos de revitalização urbana nos centros das grandes cidades, para encontrar nesta, que é uma característica da cultura pós-moderna, as oportunidades para o desenvolvimento de uma nova pastoral urbana. Considera os benefícios sociais e oportunidades criados pelos novos projetos urbanos, mas também observa as consequências negativas geradas pela exclusão dos antigos habitantes dos espaços revitalizados. De que forma a Igreja pode colaborar para uma revitalização que valorize a vida, sobretudo onde esta é mais frágil e dependente? Tomando como referenciais teóricos, Del Rio, Simões Jr. e o Documento de Aparecida, este estudo busca lançar luzes para que o anúncio de Cristo e do seu Evangelho possa penetrar de forma criativa e eficaz no coração dos novos centros urbanos, para que desperte a compaixão e a criatividade missionária para incluir os excluídos, através de projetos e parcerias entre Igreja, comércio, Estado e iniciativa privada. Assim, será possível enxergar a face da verdadeira Beleza por detrás dos centros e monumentos revitalizados.

Palavras-chave: Revitalização. Teologia pastoral. Inclusão. Evangelização.

\begin{abstract}
The present article aims to understand and reflect on the meaning of urban revitalization projects in the centers of large cities, in order to find in this, which is a characteristic of post-modern culture, the opportunities for the development of a new urban pastoral. It considers the social benefits and opportunities created by new urban projects, but also observes the negative consequences generated by the exclusion of former inhabitants from revitalized spaces. How can the Church collaborate for a revitalization that values life,
\end{abstract}


especially where it is more fragile and dependent? Taking as theoretical references Del Rio, Simões Jr. and the Document of Aparecida, from the bibliographical review, this study seeks to shed light so that the proclamation of Christ and his Gospel can creatively and effectively penetrate on the heart of new urban centers, so that it awakens compassion and missionary creativity to include the excluded, through of projects and partnerships between Church, commerce, State and private initiative. Thus, it will be possible to see the face of true Beauty behind the revitalized centers and monuments.

Keywords: Revitalization. Pastoral Theology. Inclusion. Evangelization.

\section{Introdução}

Neste artigo analisaremos os sentidos das intervenções de requalificação e revitalização nos centros das grandes cidades, e as consequências antropológicas de tais ações para as populações envolvidas e a inteira sociedade. Na dimensão pastoral este tema tornou-se bastante relevante, porque vai além de uma simples reflexão ou observação de projetos de reforma e embelezamento dos centros históricos. À primeira vista pode não parecer, mas toca diretamente na questão antropológica, pois sem o fator humano a cidade não teria razão de existir. Portanto, é importante compreender os verdadeiros objetivos, os meios usados e as consequências que se escondem por detrás desta cultura "revitalizadora" para tentar jogar uma luz nova, a luz do Evangelho, sobre os desafios e impactos sociais presentes e consequentes desta dinâmica urbana contemporânea. Somente assim, poderemos propor metas que possam colaborar para uma revitalização que faça jus ao seu significado semântico.

O período posterior à década de 1970 é, segundo Lipovetsky, caracterizado por uma sociedade pós-disciplinar, marcada pelo consumismo e pela fragilidade dos laços coletivos. ${ }^{1}$ Este pensamento corrobora a visão de Bauman ao identificar na "modernidade líquida" uma crescente falta dos pontos estáveis de orientação que antes serviam de referência para a autoconstrução do indivíduo. ${ }^{2}$ Contudo, é inegável que a modernidade e a pós-modernidade trouxeram consigo inúmeros benefícios sociais a partir da globalização e dos avanços tecnológicos.

${ }^{1}$ LIPOVESTSKY, G., Tempos hipermodernos, p. 52.

${ }^{2}$ BAUMAN, Z., Modernidade Líquida, p. 14. 
Vitalizar é restituir a vida, é dar vida nova. Seguindo esta lógica, diríamos que revitalizar significa a restituição da vida que se perdeu, ou da qual se foi privado e, neste caso, a atribuição de tal conceito às políticas urbanas indicaria uma série de medidas que devolveriam vida aos centros das cidades. Mas de que forma de vida estaríamos falando? Pois, tornam-se incompletos os projetos de revitalização quando tais medidas se resumem nas reformas estruturais de edifícios e praças, ainda que sejam para atrair antigos e novos visitantes, porém se tais empreendimentos exigirem a exclusão de pessoas consideradas indesejadas. Não estaremos matando algo fundamental para a existência de uma cidade, e privando-a de um fenômeno tipicamente humano: a relação, a abertura ao outro, a solidariedade?

Após observar o desenvolvimento do processo de revitalização nos centros das grandes cidades desejamos refletir sobre a sua relação com o trabalho pastoral da Igreja nestas áreas revitalizadas. Embora, à primeira vista possa parecer não haver relação entre os dois temas, basta um olhar atento para a questão social, para a população pobre e indesejada nas áreas revitalizadas, assim como as diversas consequências geradas pela exclusão. Basta olhar para o muro de separação que é erguido a partir da supervalorização de áreas que tornam-se acessíveis apenas a quem pode pagar por elas, enquanto alguns são privados de qualquer direito ou possibilidade. Então, surge espontânea a pergunta: como ser presença de igreja dentro das novas configurações dos centros das cidades? Para responder a esta pergunta é necessário observar se é possível fazer-se presente e anunciar a alegria do Evangelho no coração mesmo das cidades, de forma a gerar novas relações e se, além disso, é possível desenvolver um trabalho mais articulado entre governo, comércio, mercado imobiliário, igrejas e outros órgãos, para reduzir os danos sociais nos centros das cidades. Estas são apenas algumas das questões que abordaremos no presente artigo.

Será sobretudo através das pesquisas de Del Rio e de Simões Jr., que buscaremos compreender o sentido e o valor dos projetos de revitalização ao longo da história do urbanismo ocidental, e para encontrar um modelo de pastoral urbana que acompanhe as novas configurações dos centros das grandes cidades será utilizado o Documento de Aparecida, que também reflete sobre a questão urbana e dá pistas para um novo modelo de pastoral.

\section{A importância das áreas centrais nas cidades}

Para melhor compreender a importância das intervenções feitas nas áreas centrais das grandes cidades é necessário considerar a gênese e o 
desenvolvimento histórico dos projetos de revitalização urbana, sobretudo a evolução das intervenções e os inúmeros benefícios aportados aos centros das grandes cidades. Este será o objetivo da presente seção, que também refletirá acerca das mudanças antropológicas inerentes aos projetos de revitalização na sua dinâmica relacional, psicológica e social.

No período anterior à Revolução Industrial, a lógica que prevalecia na formação das grandes cidades atribuía um valor primordial às regiões centrais sobretudo por causa da sua capacidade de unificar e integrar, em um único espaço geográfico, todas as atividades e serviços importantes e necessários para os seus habitantes. Outra característica dessas áreas, era a capacidade de reunir em torno a si a maioria do patrimônio, não somente histórico, mas também arquitetônico e artístico de uma cidade, caracterizando, portanto, parte da cultura de um povo.

Segundo Del Rio estas eram as características que agregavam valor aos centros urbanos, além de um valor simbólico de poder, o que os tornavam moldáveis "aos sucessivos paradigmas imagéticos das classes dominantes". 3 Por causa desta dimensão simbólica as grandes cidades são descritas a partir do seu centro, como é o caso de Londres, Nova Iorque, São Paulo, e tantas outras.

No período pré-industrial a lógica espacial das cidades ainda era estática, seguindo o modelo medieval, tendo como núcleo central a igreja, a praça do mercado, o governo da cidade e, gradativamente as casas das famílias mais influentes. Essa lógica, segundo Lefebvre fazia do centro um lugar de encontro, de comunicação e de troca de experiência. ${ }^{4}$ Portanto, esta estrutura centrípeta tendia a identificar o espaço geofísico com o relacional e influenciava a vida social da cidade, de forma que morar no centro era um símbolo de poder e de status.

Segundo Botelho, dadas a sua "frequência e abrangência, as propostas de revitalização de centros urbanos têm ocupado um lugar importante na dinâmica contemporânea", ${ }^{5}$ mas não se trata de algo recente na lógica administrativa das grandes cidades. No século XVI, o Papa Sisto V realizou um projeto estrutural urbano em Roma, implantando na cidade eterna um novo sistema simbólico, com o intuito de facilitar o acesso dos visitantes às quatro basílicas, através da ampliação de algumas ruas. Conforme explica Del Rio, outras cidades europeias, também passaram por processos de intervenção nas suas áreas centrais, após terem sido vítimas grandes de catástrofes, como foi o caso de Lisboa e de Londres, em ambas, porém, não houve alteração do sistema

\footnotetext{
${ }^{3}$ DEL RIO, V., Desenho Urbano e Revitalização na área Portuária do Rio de Janeiro, p. 7.

${ }^{4}$ LEFEVRE, H., O direito à cidade, p. 30-32.

${ }^{5}$ BOTELHO, T. R., A revitalização da região central de Fortaleza (CE), p. 45.
} 
simbólico anterior, neste caso podemos dizer que se tratou muito mais de reconstrução do que, propriamente, revitalização. ${ }^{6}$

Ao longo dos últimos séculos é possível identificar três grandes momentos que marcaram as intervenções urbanísticas nos centros das grandes cidades e a cada um deles é designado um termo específico: o primeiro período é conhecido por embelezamento urbano e, conforme explica Simões Jr., suas principais características são a monumentalidade e as largas avenidas nas áeras centrais, porque correspondem às necessidades de fluidez viária da nova ordem econômica estabelecida. ${ }^{7}$ Deste modelo, a primeira referência é ao plano implementado pelo prefeito Haussmann na Paris de 1850. Além de Paris, Viena também representa este tipo de intervenção; em ambos os casos "as edificações públicas mais significativas eram erguidas em pontos estratégicos adquirindo um efeito visual que salientava a sua monumentalidade". ${ }^{8}$ Este modelo tornouse emblemático para várias outras cidades, inclusive na América Latina, como foi o caso de Buenos Aires, Rio de Janeiro e São Paulo.

Com a expansão da industrialização, sobretudo com o advento da modernidade, Del Rio observa que assiste-se a uma mudança gradual na lógica das cidades, resultando na perda da força unificadora das áreas centrais. Esta transformação é, ao mesmo tempo, consequência das mudanças antropológicas da época, assim como impulsionadora de mudanças nas relações sociais. Os centros reformados passam a ser espaços de circulação e negócios, não mais de encontros; e já neste período aparece um sério problema social relacionado à segregação espacial, causado pela tentativa de restrição do uso dos novos espaços com a expulsão da população pobre, ou seja, indesejada. ${ }^{9}$ A exclusão torna-se, por um lado, um aspecto presente na política revitalizadora como algo necessário, e por outro lado motiva a violência como resposta daqueles que são excluídos. É o que observa Bauman:

Hoje a exclusão não é percebida como resultado de uma momentânea e remediável má sorte, mas como algo que tem toda a aparência de definitivo. Além disso, nesse momento, a exclusão tende a ser uma via de mão única. É pouco provável que se reconstruam as pontes queimadas no passado. E são justamente a irrevogabilidade desse despejo e as

\footnotetext{
${ }^{6}$ DEL RIO, V., Desenho Urbano e Revitalização na área Portuária do Rio de Janeiro, p. 7.

${ }^{7}$ SIMÕES JR., J. G., Revitalização dos Centros Urbanos, p. 13.

${ }^{8}$ SIMÕES JR., J. G., Revitalização dos Centros Urbanos, p. 14.

${ }^{9}$ DEL RIO, V., Desenho Urbano e Revitalização na área Portuária do Rio de Janeiro, p. 14-17.
} 
escassas possibilidades de recorrer contra essa sentença que transformam os excluídos de hoje em "classes perigosas". ${ }^{10}$

Muitos projetos de revitalização deslocam os antigos moradores das áreas a serem requalificadas, sem a preocupação de inseri-los no novo desenho da cidade. Na maioria das vezes a resposta à exclusão é a violência, que gera e alimenta o medo e acaba distanciando e entrincheirando os moradores das cidades em duas classes adversas. E nesta lógica, segundo Bauman, prevalece a lei do mais forte que, "para tornar a distância intransponível, e escapar do perigo de perder ou de contaminar sua pureza local, pode ser útil reduzir a zero a tolerância e expulsar os sem-teto de lugares nos quais eles poderiam não apenas viver, mas também se fazer notar de modo invasivo e incômodo", ${ }^{11}$ assim estes são excluídos para as margens, nos lugares onde não serão vistos. Tais posturas de exclusão são construídas sobre um terreno antropológico muito perigoso, que é o egoísmo. Deste, nasce a sede de poder que alimenta projetos, que a princípio deveriam servir para o bem comum, mas acabam por favorecer grupos minoritários, tendo em vista somente o retorno financeiro.

$\mathrm{O}$ segundo momento de intervenções, denominado renovação urbana, acontece como resposta às consequências produzidas pela falta de planejamento das grandes cidades agora industrializadas. Simões Jr. sublinha que, este novo projeto surge como uma espécie de higienização dos antigos centros que estes, em decorrência da Revolução Industrial, receberam uma intensa imigração de operários que alojavam-se em torno das fábricas, quase sempre em condições sub-humanas de moradia, de trabalho e de saneamento. Com a presença destes novos moradores, os antigos habitantes emigraram para áreas mais afastadas e levaram consigo muitos dos investimentos que valorizavam o centro, alterando a sua caracterização de ponto de referência para as grandes ações sociais da cidade. ${ }^{12}$ Além de perder o seu valor central no contexto citadino, parte do patrimônio arquitetônico e cultural passou a ser subutilizado, seja pela falta de investimento, seja pela crescente degradação e violência.

Faz-se necessário reconhecer que a implantação do projeto de renovação urbana não contemplou as consequências psicológicas e sociais dos moradores que foram expulsos para que a reforma acontecesse. Daí é possível concluir que antes de ser uma verdadeira renovação, trata-se de uma remoção de tudo o que atrapalha o bom retorno financeiro para o governo, para o mercado imobiliário

\footnotetext{
${ }^{10}$ BAUMAN, Z., Confiança e Medo na Cidade, p. 23.

${ }^{11}$ BAUMAN, Z., Confiança e Medo na Cidade, p. 26.

12 SIMÕES JR., J. G., Revitalização dos Centros Urbanos, p. 15.
} 
e para o comércio. Simões Jr. enfatiza que este período é marcado por uma "grande insatisfação em seus moradores, dando origem a atitudes de vandalismo e de marginalidade que caracterizam estes ambientes modernistas". ${ }^{13}$

Outra consequência deste período é a forte descentralização das grandes cidades, através da criação de novas áreas comerciais, residenciais e de lazer, na prática, "novos centros", acompanhados de uma busca incessante por segurança e privacidade.

$\mathrm{O}$ terceiro momento, denominado revitalização urbana ou gentrificação ${ }^{14}$ realiza intervenções nos centros urbanos na "busca de uma nova vitalidade para essas áreas, tanto do ponto de vista econômico quanto funcional, social e ambiental". ${ }^{15}$ Para Simões Jr., este período põe fim a determinados paradigmas e inaugura novas tendências e posturas, como uma crescente valorização do bem-estar, a busca de referenciais mais humanos nos espaços coletivos, também a valorização da memória histórica por meio da preservação patrimonial, além da consciência ecológica, pela preocupação com o futuro do planeta. ${ }^{16}$

Trata-se do momento atual, que iniciou-se com as transformações realizadas nos centros de algumas cidades norte-americanas e em algumas metrópoles europeias, espalhando-se em seguida para as outras partes do mundo. No Brasil temos muitos exemplos desse tipo de intervenção visando nova funcionalidade e beleza às áreas preservadas, como o Projeto Corredor Cultural do Rio de Janeiro, a revitalização da Praça da Estação em Belo Horizonte, o Projeto Cultural Dragão do Mar em Fortaleza e tantos outros.

Botelho afirma que as novas transformações atraíram de novo a classe média aos distritos históricos por causa das vantagens encontradas nas suas proximidades, sobretudo pelos novos usos agregados às novas áreas centrais. ${ }^{17}$ Assim, é redesenhado o perfil do público que pode usufruir dos espaços e dos benefícios criados pela revitalização, com o perigo de erguer um muro de separação entre dois mundos opostos.

Uma rápida observação, até mesmo superficial, nas áreas revitalizadas dos centros das nossas cidades, revela os seus inúmeros benefícios. Porque, como afirma Huyssen: "a imagem da cidade propriamente dita torna-se central

\footnotetext{
${ }^{13}$ SIMÕES JR., Revitalização dos Centros Urbanos, p.16.

${ }^{14} \mathrm{O}$ termo vem do inglês gentrification, que deriva de gentry, ou seja, nobre.

${ }^{15}$ SIMÕES JR., J. G., Revitalização dos Centros Urbanos, p. 17.

${ }^{16}$ SIMÕES JR., J. G., Revitalização dos Centros Urbanos, p. 17.

${ }^{17}$ BOTELHO, T. R., A revitalização da região central de Fortaleza, p. 48.
} 
para o seu sucesso em um mundo globalmente competitivo". ${ }^{18}$ Além do patrimônio histórico, a própria cultura da cidade adquire valor de mercado dentro das estratégias de atração turística, o que pode ser vantajoso para a sua visibilidade. Resta-nos saber se as belas fachadas restauradas e belas praças e museus construídos expressam a totalidade da cultura de uma cidade; resta-nos igualmente saber se a população indesejada e expulsa das áreas revitalizadas não representa a parte frágil das grandes cidades e, por isso mesmo, é merecedora de uma atenção especial, evitando, assim, que a cidade seja privada da verdadeira vitalidade, do seu caráter humano, e seja dominada pelo medo. Devemos ainda questionar se a exclusão não viola os direitos que promovem e garantem a dignidade do ser humano.

Toda exclusão afirma e defende o direito de pertença do lugar que se pretende proteger, por isso a aceitação pacífica da higienização social realizada nos centros das grandes cidades concorda com a segregação de classes. Por isso é urgente questionar: a quem pertence o centro? Esta pergunta não deve ser respondida a partir de bases utilitaristas, mas antropológicas, e aqui as igrejas têm muito a contribuir, pois a atração pela beleza, o medo da violência, o desejo de realizar grandes obras, tudo isso pode ser via de acesso para o anúncio do Evangelho e a implantação da semente do Reino de Deus no coração dos centros das cidades. Para que isto aconteça, é necessário investir não somente em mudanças estruturais, mas sobretudo em mudanças relacionais.

\section{Por uma revitalização que re-vitaliza}

A análise história realizada na seção anterior possibilita um novo passo: a reflexão acerca do papel da Igreja dentro deste novo cenário urbano. É necessário, portanto, observar a questão antropológica, pois todos nós assistimos, admiramos, e nos beneficiamos com a nova imagem dos centros das nossas cidades. Porém, a beleza externa não deve nos tornar insensíveis e indiferentes a um problema que está diretamente ligado à política revitalizadora, que é a situação da população de rua. A indiferença não seria uma espécie de chancela de uma mentalidade utilitarista, que considera o pobre e o morador de rua um mal social do qual é necessário livrar-se para protegerse? Seriam eles menos humanos e, por isso, menos dignos de atenção do que as ruas e as paredes dos centros das cidades?

Partindo da ideia de que a esfera urbana vai muito além da dimensão geoespacial ou infra estrutural, mas diz respeito à dimensão sócio cultural, ao modo de

${ }^{18}$ HUYSSEN, A., Seduzidos pela memória, p. 100. 
pensar do ser humano contemporâneo, e que esta visão de si e do mundo reflete em todas as dimensões da sua vida, devemos, por coerência, afirmar que cada projeto de revitalização urbana revela o pensamento de um povo de uma determinada época; ao menos o pensamento dos criadores e executores deste projeto.

Se acreditamos que o morador de rua é, assim como nós, imagem e semelhança de Deus e, portanto, nosso irmão, impõe-se uma pergunta: O que iremos fazer? Porque não será possível revitalizar, ou seja, trazer vida nova aos centros das cidades se continuarmos a repetir os mesmos gestos de preconceito e de segregação presentes nas diversas etapas de revitalização do passado.

À luz do Evangelho, uma cidade nunca se tornará forte se desprezar a sua parte frágil. Ao contrário, é preciso unir forças para revitalizar o centro mais interno da cidade: o ser humano. Portanto, nesta autêntica revitalização, que passa necessariamente pela promoção da verdadeira dignidade humana, as igrejas têm muito a colaborar, porque conforme ensina a Laudato Sì (LS):

Nas condições atuais da sociedade mundial, onde há tantas desigualdades e são cada vez mais numerosas as pessoas descartadas, privadas dos direitos humanos fundamentais, o princípio do bem comum torna-se imediatamente, como consequência lógica e inevitável, um apelo à solidariedade e uma opção preferencial pelos mais pobres. Esta opção implica tirar as consequências do destino comum dos bens da terra, mas [...] exige acima de tudo contemplar a imensa dignidade do pobre à luz das mais profundas convicções de fé. Basta observar a realidade para compreender que, hoje, esta opção é uma exigência ética fundamental para a efetiva realização do bem comum. ${ }^{19}$

Quando excluímos as pessoas indesejadas dos centros das cidades, estamos estabelecendo o perfil dos usuários desejados. Uma atitude como esta não traz vitalidade para a cidade, ao contrário, contamina as relações sociais, estabelece como critério de relação não a pessoa e sim a sua posição social. A aceitação pacífica da exclusão social também exclui a solidariedade como característica humana, além de justificar o individualismo como modelo cultural. A exclusão polariza a sociedade, porque parte do princípio que o valor do ser humano está no resultado daquilo que é capaz de produzir, de acordo com as possibilidades de retorno financeiro para os protagonistas da revitalização. Enquanto as relações humanas e todos os seus projetos não estiverem alicerçados na base segura que Cristo apresentou, a saber, que há um só Deus e Pai de todos, e que esse Deus não faz acepção de pessoas (Mt 5,45),

${ }^{19} \operatorname{LS} 158$. 
será difícil transformar e reestabelecer relações sociais justas e fraternas. Contra o mal da exclusão, Francisco adverte na encíclica Evangelii Gaudium (EG):

Com a exclusão, fere-se, na própria raiz, a pertença à sociedade onde se vive, pois quem vive nas favelas, na periferia ou sem poder já não está nela, mas fora. Os excluídos não são "explorados", mas resíduos, "sobras". Neste contexto, alguns defendem ainda teorias da "recaída favorável" que pressupõem que todo o crescimento econômico, favorecido pelo livre mercado, consegue por si mesmo produzir maior equidade e inclusão social no mundo. Esta opinião, que nunca foi confirmada pelos fatos, exprime uma confiança vaga e ingênua na bondade daqueles que detêm o poder econômico e nos mecanismos sacralizados do sistema econômico reinante. Entretanto, os excluídos continuam a esperar. Para poder apoiar um estilo de vida que exclui os outros ou mesmo entusiasmar-se com este ideal egoísta, desenvolveu-se uma globalização da indiferença. Quase sem nos dar conta, tornamo-nos incapazes de nos compadecer ao ouvir os clamores alheios, já que não choramos à vista do drama dos outros, nem nos interessamos por cuidar deles, como se tudo fosse uma responsabilidade de outrem, que não nos incumbe. ${ }^{20}$

No seu livro Dogma e Anúncio, Joseph Ratzinger reconhece que essa fraternidade, que parte da única filiação divina, se torna um imperativo urgente e que nenhum fiel pode contentar-se com uma fraternidade abstrata, mas deve imitar a ação do Pai, que entrou "na facticidade da vida e do sofrimento humano", ${ }^{21}$ para revelar aos seres humanos esta verdade e ajudá-los a viver tal descoberta na prática.

O Documento de Aparecida (DAp) também afirma que Deus vive na cidade e que "as sombras que marcam o cotidiano das cidades, como por exemplo a violência, pobreza, individualismo e exclusão, não nos podem impedir que busquemos e contemplemos o Deus da vida também nos ambientes urbanos".22 Se Deus habita na cidade, precisamos, então, ser capazes de reconhecê-Lo, e isso não será possível se também nós fecharmos os olhos diante daqueles com os quais Jesus quis se identificar, revelando-nos, dessa forma, como poderemos amá-Lo concretamente (Mt 25,31-46).

Harvey Cox observa que a Igreja é responsável por servir e curar a cidade, e explica que a cidade padece das mesmas feridas presentes na alma do

\footnotetext{
${ }^{20}$ EG 54.

${ }^{21}$ RATZINGER, J., Dogma e Anúncio, p. 213.

22 DAp 514.
} 
ser humano urbano-secular. ${ }^{23} \mathrm{O}$ primeiro passo para exercer este serviço é, portanto, identificar a enfermidade da qual a cidade padece, e ao fazer isso se evidenciará que a doença não é o pobre ou o morador de rua, mas a miopia espiritual que impede de ter um olhar adequado sobre si e sobre o outro.

Tendo chegado ao reconhecimento desta fragilidade, faz-se urgente mudar a raiz das relações sociais. É inaceitável aceitar que se considere o pobre que dorme, transita e mendiga nos centros urbanos como um ser sub-humano, indigno dos mesmos direitos humanos que os demais membros da sociedade. É inaceitável que os mais vulneráveis socialmente continuem a ser tratados como seres invisíveis, e descartadas por uma cultura na qual cresce a indiferença.

O Compêndio de Doutrina Social da Igreja ensina que, embora a missão da Igreja não seja a de ocupar-se de todos os aspectos da vida em sociedade, faz parte dos seus direitos e deveres "elaborar uma doutrina social própria e com ela exercer influxo sobre a sociedade e as suas estruturas, mediante as responsabilidades e as tarefas que esta doutrina suscita". ${ }^{24}$ Para o êxito desta missão, em primeiro lugar é necessário fortalecer a identidade cristã de cada um dos seus membros, para que o Evangelho se torne vida nas próprias ações cotidianas. Ou seja, o serviço da Igreja à sociedade parte de uma experiência pessoal e concreta com Cristo, porque ela:

Não é uma organização assistencial, uma empresa, uma ONG, mas uma comunidade de pessoas, animadas pela ação do Espírito Santo, que viveram e vivem a maravilha do encontro com Jesus Cristo e desejam partilhar esta experiência de profunda alegria, partilhar a Mensagem de salvação que o Senhor nos trouxe. É justamente o Espírito Santo que guia a Igreja neste caminho. ${ }^{25}$

A missão, portanto, é fruto de uma experiência e da obediência ao mandato do Senhor, porém é importante que os vários órgãos eclesiais que trabalham incansavelmente em favor dos mais necessitados saibam dialogar entre si, e também dialogar com outras confissões igualmente empenhadas no exercício da misericórdia em favor dos pobres. A solidariedade é um instrumento para reconstruir a unidade e, como ensina Francisco, "a unidade é superior ao conflito", ${ }^{26}$ por isso a articulação e partilha de projetos, conhecimento e força, tornarão o serviço mais eficaz.

${ }^{23}$ COX, H., A cidade secular, p. 163.

${ }^{24}$ COMPÊNDIO DE DOUTRINA SOCIAL DA IGREJA, 68-69.

${ }^{25}$ FRANCISCO, PP., Mensagem para o Dia Mundial das Missões 2013, 4.

${ }^{26}$ EG 228. 
Embora os trabalhos de ação social realizados pelas igrejas em favor da população de rua sejam, muitas vezes, reduzidos no seu alcance pela falta de recursos financeiros, isso não reduz a sua grandeza, pois a caridade não se limita apenas ao seu aspecto material, pois juntamente com a distribuição de alimentos e roupas, distribuem alegria, presença, escuta, aconselhamento, em outras palavras, humanidade. Mas é preciso fazer mais. Não é suficiente dar o necessário para cada dia, é preciso criar estratégias para oferecer oportunidades novas que possam mudar vidas. E para reduzir ao mínimo possível as reincidências, é fundamental mediar a restauração da dignidade perdida, para fazer emergir o que há de melhor em cada um. Isso só é possível se na base de todo o serviço missionário estiver o anúncio explícito de Jesus Cristo, para que, na experiência com o seu amor, cada pessoa descubra a sua "vocação sublime" ${ }^{27}$ e a sua altíssima dignidade de filho de Deus.

\section{3. "Primeirear" como pastoral urbana nos centros das grandes cidades}

Utilizando o neologismo empregado pelo Papa Francisco ao falar da missão da Igreja em saída, ${ }^{28}$ a presente seção deseja fornecer possibilidades de ação missionária e social para uma verdadeira revitalização no coração de cada cidade. O fundamento utilizado será o Documento de Aparecida (DAp), pois este oferece propostas para uma nova pastoral urbana "para que os habitantes dos centros urbanos e de suas periferias, cristãos ou não cristãos, possam encontrar em Cristo a plenitude de vida". ${ }^{29}$ As propostas apresentadas têm como centro o anúncio explícito de Cristo e do seu Evangelho como resposta aos grandes desafios da crescente urbanização. Dentre elas, duas merecem um destaque especial no presente artigo:

1. Ofereça atenção especial ao mundo do sofrimento urbano, isto é, que cuide dos caídos ao longo do caminho e aos que se encontram nos hospitais, encarcerados, excluídos, dependentes de drogas, habitantes das novas periferias, nas novas urbanizações e das famílias que, desintegradas, convivem de fato. ${ }^{30}$

2. Fomente a pastoral da acolhida aos que chegam à cidade e aos que já vivem nela, passando de um passivo esperar a um ativo buscar e chegar aos que estão longe com novas estratégias, tais como visitas às casas, o

\footnotetext{
${ }^{27}$ GS 22.

${ }^{28}$ EG 24.

${ }^{29}$ DAp 518.

${ }^{30}$ DAp 517.
} 
uso dos novos meios de comunicação social e a constante proximidade ao que constitui para cada pessoa o seu dia-a-dia. ${ }^{31}$

Primeirear como pastoral urbana é tomar a iniciativa em exercer a misericórdia no cuidado com os mais vulneráveis; assim como ousar em criar projetos, articulando parecerias com os demais setores da sociedade na busca do bem comum. As igrejas devem oferecer o seu serviço de uma evangelização integral, através de centros de acolhimento verdadeiramente humanos, onde cada um é acolhido com amor e dignidade; os demais organismos devem oferecer, por exemplo, segurança, alimentação, alfabetização e cursos profissionalizantes que ajudem na reinserção social e promova a dignidade humana. Juntos devem cuidar da saúde psicológica dessas pessoas, oferecendo a cada uma o cuidado necessário.

Na realização de uma missão tão exigente faz-se necessário que haja unidade entre os diversos setores em cada diocese, criando uma pastoral urbana composta por pastorais sociais, Caritas, Comunidades Novas, Pastoral jovem e demais setores que podem colaborar no planejamento e na execução de projetos em favor do verdadeiro bem social e na missão de uma Igreja verdadeiramente "em saída".

Primeirear como pastoral urbana nos centros das grandes cidades, significa evangelizar com criatividade. É preciso levar a presença do Cristo que acolhe, que escuta e que perdoa para os novos centros urbanos, e ali semear a alegria do Evangelho, também por meio da beleza da arte, da música, do esporte, etc. Outra forma criativa e eficaz de ser presença de igreja nas grandes cidades é transformar lugares comuns, como por exemplo, lanchonetes, cafés, livrarias, de simples espaços comerciais em espaços de re-vitalização humana e cristã. Ou seja, revitalizar é criar espaços de lazer, dando-lhes novos significados e novos usos, transformando-os em locais de encontro com Deus, através da disponibilidade de pessoas que acolhem, escutam, aconselham e rezam; como já acontece em diversos lugares do mundo. Dessa forma, o shopping, o centro histórico, a praia, qualquer lugar torna-se apropriado para possibilitar uma experiência com Jesus Cristo, o único que pode dar verdadeiro sentido à vida.

Também não devem ser esquecidos os que passam pelas cidades na qualidade de visitantes e turistas. Deve-se pensar em novas formas de acolhida e de anúncio para aqueles que estão apenas de passagem, por serem eles também dignos da atenção pastoral da Igreja. Fará muita diferença se, ao

${ }^{31}$ DAp 517. 
entrarem nos templos religiosos, ainda que com o simples interesse turístico, encontrarem sempre pessoas que os acolham, que os escutem, que lhes apresente as atividades promovidas naquele período, nas quais eles serão bemvindos. Esta seria uma verdadeira pastoral do acolhimento, pois ser Igreja "em saída" é também saber acolher.

\section{Conclusão}

A revitalização urbana é uma característica da cultura contemporânea, e as marcas que ela deixa ao longo da história estão visíveis nas novas e belas paisagens que produzem, nas novas relações que elas estabelecem, mas também há marcas deixadas nos conflitos gerados pela exclusão dos mais pobres, conforme visto acima. É necessário, portanto, que o anúncio do Evangelho também imprima uma marca nova no coração dos novos centros urbanos e, a partir deles, atinja outro centro mais profundo, o coração do ser humano, que tem sede da verdadeira Beleza.

O coração humano tem sede de beleza porque tem sede de Deus, pois o mundo criado traz em si a marca do seu Criador. Assim, sabendo que através da experiência empírica o ser humano busca algo que lhe remeta à plenitude ou à perfeição, a cultura revitalizadora pode ser um instrumento eficaz para uma nova evangelização capaz de unificar as pessoas de boa vontade em favor dos mais frágeis. Não se pode esquecer que, de modo paradoxal que Cristo os escolheu como ícones da sua presença no mundo. A Igreja, portanto, ao anunciar e trabalhar pela edificação do Reino de Deus, deve promover a unidade entre esses dois extremos, promovendo a cultura do encontro também nos centros urbanos.

Há muitos grupos, instituições e comunidades, que se empenham para reduzir os danos da miséria na vida da população de rua, especialmente nos grandes centros urbanos; cada trabalho desse tem grande valor, e consegue aliviar, mesmo que momentaneamente, necessidades urgentes dessa população necessitada, mas não basta. É necessário que haja uma articulação real entre os diversos setores da sociedade interessados em solucionar "o problema" que diz respeito a todos. Aqui também a Igreja deve primeirear na missão de fazer unidade, criando parcerias entre as igrejas, o Estado, o comércio, o mercado imobiliário e as demais instituições, na tentativa de tornar mais eficazes tais ações. Esta é uma ação de misericórdia na qual todos ganham, pois, o destinatário último de cada ato feito por amor é o próprio Cristo. 
Certamente, um trabalho articulado para reduzir o problema da população de rua nos centros das grandes cidades, não é tarefa fácil, mas também não será algo impossível, pois estamos acostumados a ver o ser humano desafiando até mesmo as leis da física e realizando projetos antes considerados impossíveis, por isso, com coragem, determinação, responsabilidade e persistência, é possível criar algo novo e duradouro para a sociedade e a cultura, sem excluir ninguém. Esta será uma verdadeira revitalização.

Cada patrimônio histórico de uma cidade é um símbolo do passado daquela sociedade e tem um valor que não deve ser esquecido, e isso já justificaria todo o esforço para torná-lo funcional. Mas a história não é feita apenas com a preservação do passado, porque também nós estamos construindo a história com as nossas ações presentes; portanto, se o que fazemos hoje é construir mais muros do que pontes, o futuro interpretará o nosso presente como um passado a ser revitalizado. Temos, portanto, um compromisso inadiável com as futuras gerações, e este compromisso passa, necessariamente, pela coragem de viver o Evangelho com toda a sua radicalidade, também no campo social.

\section{Referências bibliográficas}

BAUMAN, Z. Modernidade Líquida. Rio de Janeiro: Zahar, 2014.

BAUMAN, Z. Confiança e Medo na Cidade. Rio de Janeiro: Zahar, 2009.

BOTELHO, T. R. A revitalização da região central de Fortaleza (CE): novos usos dos espaços públicos da cidade. In: FRUGOLI JR., H. (Org.). As cidades e seus agentes: Práticas e representações. Belo Horizonte: PUC Minas e Eduspe, 2006. p. 45-67.

CELAM. Documento de Aparecida. Texto conclusivo da V Conferência Geral do Episcopado Latino Americano e do Caribe. Brasília: CNBB, 2007.

CONCÍLIO VATICANO II. Constituição Pastoral Gaudium et Spes. Sobre a Igreja no mundo de hoje. São Paulo: Paulinas, 2017.

COX, H. A cidade secular. A secularização e a urbanização na perspectiva teológica. Santo André: Academia Cristã, 2015.

DEL RIO, V. Desenho Urbano e Revitalização na área Portuária do Rio de Janeiro. A contribuição do Estudo da Percepção Ambiental. São Paulo, 1991. 548p. Tese. Faculdade de Arquitetura e Urbanismo, Universidade de São Paulo. 
FRANCISCO, PP. Mensagem para o Dia Mundial das Missões 2013. Disponível em: < https://bityli.com/Jq811>. Acesso: 30 jul. 2021.

FRANCISCO, PP. Carta Encíclica Laudato Sí'. Sobre o cuidado da casa comum. São Paulo: Paulus, 2015.

FRANCISCO, PP. Exortação Apostólica Evangelii Gaudium. Sobre o anúncio do Evangelho no mundo atual. São Paulo: Paulus, 2013.

HUYSSEN, A. Seduzidos pela memória: Arquitetura, Monumento, Mídia. Rio de Janeiro: Aeroplano, 2000.

LEFEBVRE, H. O direito à cidade. São Paulo: Centauro, 2001. PONTIFÍCIO CONSELHO JUSTIÇA E PAZ. Compêndio de Doutrina Social da Igreja. São Paulo: Paulinas, 2017.

LIPOVESTSKY, G. Tempos hipermodernos. Pinheiros, SP: Editora Barcarolla, 2011.

RATZINGER, J. Dogma e Anúncio. São Paulo: Loyola, 2007.

SIMÕES JR., J. G. Revitalização dos Centros Urbanos. Revista Polis, n. 19, p. 5-69, 1994.

Josefa Alves dos Santos

Doutoranda em Teologia Sistemática pela Pontifícia Universidade Católica do Rio de Janeiro Rio de Janeiro / RJ - Brasil E-mail:shjosefa@gmail.com

Recebido em: 31/07/2021

Aprovado em: 02/12/2021 